\title{
Cambio climático y pobreza
}

\section{Climate Change and Poverty}

\author{
María Paula Casanova ${ }^{1}$
}

\begin{abstract}
Resumen
El hombre necesita estar en armonía con la naturaleza que le otorga lo necesario para vivir $y$, desde un punto de vista teológico, tiene además la responsabilidad de comportarse como un buen administrador ya que de ello depende la posibilidad de vida tanto de los seres humanos como de las demás criaturas. El consumo desmedido de los recursos de la tierra nos ha llevado a la situación actual: hay una aceleración tal del cambio climático que supone un riesgo de vida para muchos de nuestros contemporáneos, pero especialmente para las futuras generaciones. Las repercusiones de estos cambios generados por las sociedades de consumo afectan especialmente a los más pobres que dependen, en su gran mayoría, de la agricultura y de la pesca para su supervivencia, y que no tienen la capacidad de adaptarse al nuevo escenario que el clima les presenta.
\end{abstract}

Palabras clave: cambio climático, pobreza, bien común, migraciones.

\begin{abstract}
Man needs to be in harmony with nature that grants him what is necessary to live and, from a theological point of view, he also has the responsibility to behave as a good administrator since the possibility of life of both human beings and other creatures depends on it. The excessive consumption of the Earth's resources has brought us to the present situation: there is such an acceleration of climate change that it is a risk to life for many of our contemporaries, but especially for future generations.

The repercussions of these changes, generated by consumer societies, especially affect the poorest who depend, for the most part, on agriculture and fishing for their survival, and who do not have the capacity to adapt to the new scenario that the climate presents to them.
\end{abstract}

Keywords: climate change, poverty, common good, migration.

\section{Doctrina Social de la Iglesia / ensayo científico}

Citar: Casanova, M. P. (2020). Cambio climático y pobreza. Omnia. Derecho y sociedad, 3 (3), pp. 83-100.

\footnotetext{
1 Universidad Católica de Salta. Doctora en Teología por el Ateneo Pontificio Regina Apostolorum (Roma). Docente de las cátedras Teología I y Teología II en la carrera de Abogacía de la Universidad Católica de Salta, Delegación Neuquén. mpcasanova@ucasal.edu.ar
} 


\section{INTRODUCCIÓN}

El clima es un bien común ${ }^{2}$ que posee condiciones esenciales para la vida humana y que, por eso, debería formar parte de la preocupación de todos. Cuando este varía a un ritmo más acelerado que lo natural — producto del consumo despiadado de las sociedades principalmente occidentales que están arrasando con la naturaleza - se genera un desequilibrio con graves consecuencias para la humanidad que repercute, especialmente, en las personas o las poblaciones más pobres.

Aunque en muchos se observa la negación del problema, la indiferencia, la resignación cómoda o la confianza ciega en la solución técnica (véase Francisco, 2015, n. ${ }^{\circ} 49$ ), como cristianos no podemos permitirnos asumir ninguna de estas posturas, ya que la preocupación por la naturaleza, la justicia con los pobres, el compromiso con la sociedad y la paz interior son inseparables (Francisco, 2015, n. ${ }^{\circ} 11$ ).

En estas páginas, expondremos la relación entre el cambio climático y la pobreza. Para ello, en primer lugar, abarcaremos la problemática desde el punto de vista teológico, de la doctrina social de la Iglesia y de la ética de la responsabilidad. Luego, nos detendremos a considerar la situación de la agricultura, una de las realidades más representativas para conocer el drama del cambio climático, en tanto es una actividad que vive la ambivalencia de involucrar a quien acelera el cambio y, también, a quien más lo sufre, además de ser la fuente de subsistencia de la mayor parte de las personas que viven en la pobreza a nivel mundial. Seguiremos con la presentación del drama de las migraciones climáticas y terminaremos presentando la preocupación por una actividad que quiere desarrollarse cada vez más en la Argentina y que es causal de aumento de las temperaturas y conlleva un aumento de la pobreza: la megaminería.

\section{TEOLOGÍA, DOCTRINA SOCIAL DE LA IGLESIA Y ÉTICA}

El medioambiente es un don que Dios le confía al hombre para su trabajo y su realización, pero no es algo absolutamente ajeno a él, es decir, algo que solo da posibilidad de cultura al hombre, sino que, de alguna manera, también es parte de él. Nuestra constitución de seres espirituales y materiales nos obliga a tomar conciencia de nuestra pertenencia a esta tierra que necesitamos para vivir. En este sentido, los pueblos indígenas hablan de la $\mathrm{Pa}-$ chamama: de manera panteísta, ven en la tierra a un ser que nutre y da vida. Los cristianos sabemos que Dios es el único dador de vida, y que esta vida recibida solo puede desarrollarse si lo hace en armonía y si sabe servirse sana y responsablemente de los bienes que la tierra le ofrece: "la relación del hombre con el mundo es un elemento constitutivo de la identidad humana. Se trata de una relación que nace como fruto de una unión todavía más profunda, del hombre con Dios" (Pontificio Consejo Justicia y Paz, 2005, n. ${ }^{\circ}$ 452). De hecho, el desorden producido por el pecado del hombre también afecta el equilibrio ambiental, de manera tal que "la creación entera espera la manifestación de los hijos de Dios" (Rom 8,19).

A su vez, podemos ver la importancia de esta relación en la salvación otorgada por Jesucristo, que la realiza "en" el mundo y que se

\footnotetext{
2 Recordemos que el bien común es el "conjunto de condiciones de la vida social que hacen posible a las asociaciones y a cada uno de sus miembros el logro más pleno y más fácil de la propia perfección" (Pontificio Consejo Justicia y Paz, $\left.2005, n .^{\circ} 164\right)$.
} 
sirve de elementos de la naturaleza tanto para revelar su poder e identidad (camina sobre el agua, calma la tempestad, cambia el agua en vino), como para hacerse presente u otorgar la gracia por medio de los sacramentos, para lo cual hace uso del agua, el aceite, el trigo, el fruto de la vid.

Sin embargo, son muchos los movimientos ambientalistas que acusan a la tradición judeocristiana de la actual degradación ambiental, para lo cual se basan en una incorrecta interpretación del texto bíblico y dan por supuesto que, al haber puesto Dios al hombre por encima de las demás criaturas, lo autorizaba a un uso despiadado de la creación.

Esta particular lectura de los textos bíblicos está lejos de ser la interpretación que, al menos, hacen de ellos las iglesias cristianas. Para los cristianos $^{3}$, el hombre es puesto por Dios como custodio de lo creado y posee el mandato de trabajarlo, crear cultura, hacer que cada cosa llegue a la plenitud que posee en germen y espera alcanzar. Por eso, los seres humanos deben saber que son administradores y no dueños absolutos, y que, como tales, tienen la responsabilidad de actuar según el mandato recibido.

Así y todo, con su pecado, el hombre provoca un desorden que afecta inevitablemente a toda la creación y que es evidente no solo a los ojos de los creyentes, sino también para aquellos que no tienen fe: la crisis ecológica es un problema moral que tiene su raíz principalmente en "la falta de respeto a la vida" (Juan Pablo II, 1990, n. ${ }^{\circ}$ 7) y tiene su solución en un cambio de hábitos, que empieza por un consumo ético y responsable.

Por esta razón, si añadimos un significado religioso al cuidado de la creación, obtendre- mos un importante impacto en la percepción del valor de la vida y de la adecuada solución a los problemas sociales (Benedicto XVI, 2006).

La doctrina social de la Iglesia (Pontificio Consejo Justicia y Paz, 2005, n. ${ }^{\circ}$ 451-487) nos recuerda que la tutela del medio ambiente implica el deber común y universal de respetar un bien colectivo, debe tener una traducción adecuada en el ámbito jurídico y debe ser tenida en consideración en los programas de desarrollo económico de los países, especialmente si se considera que los recursos son limitados y, algunos, no renovables. De aquí que cualquier actividad económica que se sirva de recursos naturales debe ocuparse de la salvaguarda del medioambiente, calcular sus costos y prestar atención a la relación entre su actividad y los cambios climáticos que esta pueda originar.

No obstante, a todos estos cuidados debe agregarse el deber de compartir los recursos equitativamente, según la justicia y la caridad ya que, muchas veces, los pueblos en vía de desarrollo alimentan el progreso de los países más ricos a costa de su presente y su futuro, y pagan el precio más caro a causa del deterioro ecológico. Es fundamental considerar que "un verdadero planteo ecológico se convierte siempre en un planteo social, que debe integrar la justicia en las discusiones sobre el ambiente, para escuchar tanto el clamor de la tierra como el clamor de los pobres" (Francisco, 2015, n. $\left.{ }^{\circ} 14\right)$.

En la lucha contra el cambio climático, hay responsabilidades diversificadas y es necesario ponerse del lado de los más pobres en un debate que generalmente es dominado por los intereses de los más poderosos. Un dato para reflexionar: el veinte por ciento de la población mundial consume recursos en tal medida

\footnotetext{
3 Para leer algunas declaraciones de distintas iglesias cristianas comprometidas con el cuidado de la creación, véase Movimiento Católico por el Clima (s.f.) y Earth Ministry (s.f.).
} 
que roba a las naciones pobres y a las futuras generaciones lo que necesitan para sobrevivir (Francisco, 2015, n. ${ }^{\circ} 52$ y 95).

En el año 1991, Juan Pablo II decía que es "necesario abandonar una mentalidad que considera a los pobres - personas y puebloscomo un fardo o como molestos e inoportunos, ávidos de consumir lo que otros han producido" (n. $\left.{ }^{\circ} 28\right)$. En nuestros días, esta misma mentalidad es la que ha generado en los países del primer mundo, en particular, pero en todo el mundo en general, una ola xenófoba que considera al inmigrante un potencial delincuente que llegar para menoscabar el estado de bienestar. Este rechazo no es al extranjero en sí mismo, puesto que todos están felices con los turistas o inmigrantes adinerados, sino que se ha gestado en nuestras sociedades un miedo al pobre al que Adela Cortina (2017) ha denominado "aporofobia" y que, desde el 2017, ya forma parte de las palabras aceptadas por la Real Academia Española.

Por estos motivos, es muy importante que los países llamados "desarrollados" tomen conciencia de la responsabilidad que tienen con respecto a la situación de subdesarrollo de tantos otros, ante lo cual tienen la tarea de buscar una forma de remediarlo. De hecho, en muchos países persiste una especie de colonización económica donde grandes empresas extranjeras, que no se comprometen con el desarrollo del país, juegan roles decisivos en las economías y poseen gran influencia política (Pablo $\mathrm{VI}, \mathrm{n} .^{\circ} 21$ ). Pero también es muy importante que todas las personas se cuestionen si con sus hábitos de consumo no están generando pobreza, esa misma pobreza que provoca el rechazo cuando viene a tocarnos la puerta a pedirnos por caridad, aquello que le debemos por justicia.

El principio del destino universal de los bienes de la doctrina social de la Iglesia (DSI) llama la atención sobre la relación existente entre la crisis ambiental y la pobreza, en tanto esta crisis es generada principalmente por las sociedades de consumo, pero es padecida con sus peores consecuencias por los más pobres. Estos viven en tierras sujetas a la erosión y a la desertización o en suburbios contaminados de las ciudades, se ven obligados a migrar en condiciones de absoluta vulnerabilidad, se encuentran inmersos en conflictos armados que no iniciaron, sufren la escasez de agua potable, lo cual lleva conexo el incremento del precio de los alimentos, las enfermedades y las muertes por falta de higiene, entre otras dificultades. Asimismo, son muchos los pobres que, además de vivir en lugares particularmente afectados por el calentamiento global, subsisten gracias a las reservas naturales y a los servicios ecosistémicos, no tienen otra actividad financiera o recursos que les permita adaptarse a los vaivenes climáticos y poseen poco o nulo acceso a servicios sociales. Mencionaremos algunos ejemplos: el agotamiento de las reservas ictícolas perjudica especialmente a quienes viven de la pesca artesanal; la contaminación del agua daña especialmente a los más pobres, quienes tienen dificultades para comprar agua en botella; la elevación del nivel del mar afecta principalmente a los pobladores de los litorales, que no tienen cómo mudarse (Francisco, 2015, n. ${ }^{\circ} 48$ ); con frecuencia, las ciudades - los países más ricos descartan sin cuidado elementos que contaminan el aire y la tierra de los sectores más pobres (tales como residuos domiciliarios, comerciales, patógenos, electrónicos, industriales, tóxicos, radiactivos) y que, luego, son inhalados, absorbidos y/o manipulados por ellos. Hay muchos residuos industriales o químicos que se utilizan en las ciudades y/o en las zonas rurales que pueden producir un efecto de bioacumulación en los pobladores de las zonas cercanas (Francisco, 
2015, n. $\left.{ }^{\circ} 20-22\right)$. Sin ir más lejos, en la provincia de Chubut, durante el año 2010, el gobernador Das Neves autorizó la creación de un basurero nuclear en la zona de Gastre. Si bien el basurero "aparentemente" no se constituyó a causa las presiones recibidas, hay indicios que hacen sospechar su existencia con todo lo que eso significa para los lugareños (véase Alejandro Beletzky, 2018 y El Patagónico, 2016).

Si bien es cierto que no todas las naciones tienen la misma responsabilidad en esta situación, el cuidado del ambiente, la promoción de un desarrollo sostenible y la atención al cambio climático son cuestiones de extrema relevancia para la familia humana entera, ya que es imposible ignorar las implicancias éticas presentes en todos los desarrollos económicos y sociales.

La ciencia nos muestra cómo las acciones humanas de una región determinada pueden provocar repercusiones a escala mundial, de manera tal que el desprecio por el ambiente daña la coexistencia humana y traiciona su dignidad (Benedicto XVI, 2006). Por eso, la humanidad entera tiene el deber de comprometerse contra el uso indiscriminado de los bienes de la tierra y debe establecer límites éticos y morales para que su comportamiento no se convierta en un desafío o una amenaza. En este sentido, el Papa Benedicto XVI (como se cita en Milvia Morciano, 2012) manifestaba que es muy importante la educación en la ética de la responsabilidad. Esta ética "relativamente nueva" fue planteada y desarrollada por el filósofo Hans Jonas (1995), en el año 1979. Se distingue de la ética antigua que se concentraba en la moralidad del acto y en las consecuencias que este podía traer para el prójimo. Hoy, en cambio, se hace necesario alargar el horizonte y considerar también como prójimo al que no es contemporáneo. A su vez, esta nueva ética toma en consideración la irreversibilidad de las consecuencias de algunas acciones.
Según el mismo filósofo, hasta ese momento, todas las corrientes éticas consideraban la existencia de una naturaleza humana que era inmutable y normativa. Pero la técnica moderna ha abierto una dimensión totalmente nueva de relevancia ética no prevista en los cánones tradicionales, en tanto las acciones se manifiestan de modo distinto a como lo han hecho a lo largo de todos los tiempos. Porque, si bien siempre ha existido la técnica, en la antigüedad, las intervenciones del hombre en la naturaleza eran esencialmente superficiales e incapaces de dañar su permanente equilibrio, lo que hacía que la naturaleza no sea considerada como objeto de responsabilidad humana, sino que se asumió que ella cuidaba a sí misma y, de alguna manera, cuidaba también del hombre. En otras palabras, la naturaleza no se pensaba desde la ética sino desde la capacidad de invención, pero esta situación debió modificarse cuando se hizo presente su vulnerabilidad a partir de la manifestación de los daños causados.

La ética de la responsabilidad incluye los preceptos de la ética antigua: honradez, justicia, caridad, entre otros. Sin embargo, como la acción y sus efectos ya no son los mismos, se requiere una nueva dimensión que es la de la responsabilidad. Otra diferencia con la ética tradicional es que ella solo tenía en cuenta los efectos de los actos que eran contemporáneos y se creía que no eran acumulativos, aunque sabemos que las antiguas intervenciones sobre la naturaleza también fueron dejando su huella. Ahora estamos ante un panorama diferente: los efectos de nuestros actos - por ejemplo, de nuestros hábitos de consumodejan una huella de carbono que incrementa la variación climática, se acumula y nos afecta a nosotros, a nuestros contemporáneos que viven a kilómetros de distancia y a aquellos que vivirán en el futuro, y muchas veces el daño que podemos generar es irreversible. 
Jonas (1995) retoma el imperativo categórico de Kant (1980) - "Obra de tal modo que puedas querer que tu máxima se convierta en ley universal" (p. 64)—, y lo "actualiza" a la nueva situación de la humanidad:

... obra de tal modo que los efectos de tu acción sean compatibles con la permanencia de una vida humana auténtica en la tierra o, expresado negativamente, obra de tal modo que los efectos de tu acción no sean destructivos para la futura posibilidad de esa vida. (p. 40)

Este nuevo imperativo dice que nos es lícito arriesgar nuestra vida, pero no lo es arriesgar la existencia de las generaciones futuras por causa de nuestro actuar.

\section{EL CAMBIO CLIMÁTICO}

La aceleración del normal y esperable cambio climático generado por el consumo desenfrenado del hombre ha llevado a la Tierra a un aumento excesivo de su temperatura: se ha incrementado en $1^{\circ} \mathrm{C}$ por encima de su nivel preindustrial, con ciclos de retroalimentación y amplificación polar que resultó un aumento de $3{ }^{\circ} \mathrm{C}$ en el noroeste de Canadá (The Lancet, 2019). Esto ha generado un aumento desmedido del efecto invernadero que generan los gases emitidos por el trabajo humano, lo cual tiene importantes y graves repercusiones para la vida de todos los hombres del presente y, especialmente, del futuro.

Por esto, es que podemos afirmar que nos encontramos en una hora decisiva para limitar los daños producidos, disminuir la velocidad del incremento de las altas de temperatura e impedir que las alteraciones sean irreparables. El objetivo propuesto es reducir el calentamiento a $1,5^{\circ} \mathrm{C}$ que, aunque sigue siendo alto, permite moderar los riesgos que se presentan con un aumento de la temperatura de $2^{\circ} \mathrm{C}^{4}$.

Las poblaciones más desfavorecidas y vulnerables, como algunos pueblos indígenas o comunidades que subsisten gracias al trabajo agrícola o costero, son las que más sufren el cambio climático y, por este motivo, su situación se verá cada vez más comprometida. Además, hay regiones que se encuentran amenazadas por estas alteraciones, como ser los ecosistemas del Ártico, las regiones áridas, los pequeños Estados insulares en desarrollo y los países menos adelantados.

Entre las consecuencias más inmediatas del cambio climático, podemos apreciar el incremento de la temperatura promedio, veranos más calurosos y la aparición de temperaturas extremas producto de la concentración de gases y el efecto invernadero ${ }^{5}$, lo cual produjo un incremento sustancial en la mortalidad cau-

\footnotetext{
${ }^{4}$ En octubre de 2018, el Grupo Intergubernamental de Expertos sobre el Cambio Climático (IPCC) publicó un informe especial sobre los impactos del calentamiento global a $1,5^{\circ} \mathrm{C}$, donde señalaba que limitar el calentamiento global a este nivel requerirá cambios rápidos, de gran alcance y sin precedentes en todos los aspectos de la sociedad. Con ventajas claras para la gente y los ecosistemas naturales, el informe encontró que la limitación del calentamiento global a $1,5^{\circ} \mathrm{C}$ comparado con $2{ }^{\circ} \mathrm{C}$ podría ir de la mano con el compromiso de asegurar una sociedad más sostenible y equitativa. Mientras estimaciones previas se enfocan en determinar el daño que se ocasionaría si la temperatura media llegara a los $2^{\circ} \mathrm{C}$, este informe establece que muchos de los impactos adversos del cambio climático se producirían ya en los $1,5^{\circ} \mathrm{C}$ (Naciones Unidas, s.f).

5 En los últimos cien años, la temperatura promedio del planeta ha aumentado $1,5^{\circ} \mathrm{C}$. Al respecto, afirma Aurelio Tobías (como se cita en Antonio Cerrillo, 2018):"Si no podemos encontrar una manera de mitigar el cambio climático, reducir la duración de las olas de calor y ayudar a las personas a adaptarse, en el futuro habrá un incremento sustancial de fallecimientos relacionados con estos fenómenos, (...) particularmente en los países más pobres, ubicados alrededor del Ecuador".
} 
sada por altas temperaturas en verano, inviernos más crudos y severos cambios en diversos procesos y ecosistemas ya que, debido a este fenómeno climático, muchas criaturas han cambiado sus rutas migratorias; también, se ven reducidas las capas polares por el deshielo de los glaciares que, a su vez, trae aparejado un aumento del nivel de los océanos que causará la pérdida de parte del territorio de algunos países ${ }^{6}$ y la acidificación de sus aguas con las graves consecuencias en los ecosistemas marinos; la salinización de los terrenos de cultivo y del agua dulce; la aparición de tormentas más poderosas (tifones, huracanes y tormentas eléctricas), que incrementaron su frecuencia e intensidad de manera tal que en algunas partes existen mediciones que aseguran que hay un $50 \%$ más de rayos que tocan tierra, en comparación con cincuenta años atrás; sequías, incendios y desapariciones de ecosistemas enteros que, al mismo tiempo, alteran los vientos y se repercutirán en las cosechas y las producciones de la zona.

El cambio climático también alterará la salud de las personas. Los más afectados en este sentido serán los niños, quienes son los que mayoritariamente ven su vida condicionada por las secuelas permanentes de la desnutrición, son los que más sufren las complicaciones por diarreas y los que padecen los efectos más graves del dengue. Desde la adolescencia, la contaminación del aire perjudica el corazón, los pulmones y los demás órganos vitales, con efecto acumulativo en el tiempo. En las etapas posteriores de la vida, cuanto mayor es la frecuencia y la intensidad de los fenómenos climáticos extremos, mayor es el peligro que sufren las familias, siendo las mujeres el grupo más vulnerable en este sentido. A su vez, las personas mayores de 65 años se ven afectadas especialmente por las olas de calor extremo y por los riesgos derivados del cambio climático, aunque algunos sean difíciles de cuantificar tales como la migración, la pobreza extrema, los conflictos armados, entre otros. Estas alteraciones impactan también en la salud mental, lo cual afecta a personas de todas las edades y nacionalidades (The Lancet, 2019).

\section{Agricultura, cambio climático y pobreza}

En la tradición cristiana, la actividad agrícola asume un significado profundo, ya sea por el esfuerzo y la fatiga que implica, o porque ofrece una experiencia privilegiada de la presencia de Dios y de su amor por sus criaturas (Benedicto XVI, 2008b).

A causa de su impacto en la agricultura, el cambio climático agudizará los efectos negativos que alteran el medioambiente, como son la degradación general de la tierra y la escasez de agua, en un momento histórico donde el aumento de la población y de los ingresos en gran parte de ella hace que se impulse la demanda de alimentos y otros derivados agrícolas.

Todos los fenómenos mencionados podrían comprometer seriamente la capacidad de la agricultura, lo cual impacta de forma directa en la capacidad de alimentación de millones de personas que viven en condiciones de pobreza (Organización de las Naciones Unidas para la Alimentación y la Agricultura [FAO], 2016). Este impacto directo se funda en que la agricultura es esencial para el suministro de alimentos, la producción de alimentos depende directamente de los recursos naturales y estos, por supuesto, están íntimamente relacionados con el clima y las condiciones meteorológicas.

La vinculación entre cambio climático y pobreza se evidencia aún con más fuerza si tene-

\footnotetext{
${ }^{6}$ Esto podría ocurrir, por ejemplo, en Vanuatu, las islas Maldivas, Kiribati, entre otros (véase Cambio Climático Global, s.f).
} 
mos en cuenta que la agricultura proporciona un medio de vida para casi dos tercios de la población mundial más pobre, es decir, para 750 millones de personas. Pero, como vimos, esta relación es bidireccional: no solo tiene impacto directo en ciertos sectores, sino que afecta también los recursos naturales. Es por ello que las industrias agrícolas tienen una importante responsabilidad a la hora de analizar el origen de las emisiones de gases con efecto invernadero, responsables del incremento del cambio climático: el dióxido de carbono, el metano y el óxido nitroso.

Mientras se intensifiquen las alteraciones del cambio climático que afectan la agricultura, será cada vez más difícil cultivar cosechas, criar animales, gestionar bosques y capturar peces en la misma forma en que se realiza hasta ahora: las malas hierbas, los insectos y las enfermedades proliferan en condiciones de temperaturas más cálidas, climas más húmedos y niveles más altos de dióxido de carbono en la atmósfera; las olas de calor suponen una amenaza directa para el ganado, puesto que el estrés térmico incrementa la vulnerabilidad de los animales a las enfermedades y los parásitos, reducirá su fertilidad y la producción de carne y leche, así como disminuirá la capacidad de pastizales y producción de piensos para los sistemas ganaderos; la pesca (especialmente aquella realizada a pequeña escala en regiones tropicales, menos desarrolladas y económicamente pobres) y la acuicultura ${ }^{7}$ que ya se encontraban en problemas debido a la pesca excesiva, la pérdida del hábitat y la contaminación del agua, sufrirán, además, la pérdida de algunas especies y el riesgo de alteración en algún eslabón de la cadena de producción. Diversas especies de peces ya están migrando hacia los polos y se espera una redistribución a gran escala del potencial de captura de la pesca marina mundial; los cambios en las precipitaciones y en la ordenación de los recursos pesqueros, el aumento de la contaminación sobre los recursos de agua dulce y la frecuencia e intensidad de los fenómenos climáticos extremos afectan de manera considerable la producción de la pesca y la acuicultura continental.

El cambio climático también incide negativamente sobre los bosques que generan trabajo para más de cien millones de personas y sustentan los medios de vida de gran parte de la población rural del mundo, puesto que limitan su capacidad para proporcionar bienes y servicios esenciales a causa de la pérdida de importantes especies, la disminución de los rendimientos y el incremento, tanto en frecuencia como en intensidad, de las tormentas y otras perturbaciones meteorológicas. Al mismo tiempo, los bosques cumplen un rol fundamental a la hora de pensar en el abastecimiento hídrico limpio y fiable, la protección contra desprendimientos, erosión y degradación de la tierra, la provisión de hábitats de animales acuáticos y terrestres, el suministro de productos madereros, etc. Tanto el incremento de las temperaturas como las variaciones en las precipitaciones están aumentando la mortalidad de los árboles que, junto con las sequías, favorecen el aumento de los incendios.

Es menester aclarar que el cambio climático también proporciona algunos beneficios sobre la agricultura, y que hasta el año 2030 se espera que los efectos benéficos y maléficos puedan contrarrestarse. No obstante, luego de esa fecha, las proyecciones son fundamentalmente negativas.

La importancia de la agricultura en nuestro estudio es fundamental, ya que es el canal

\footnotetext{
7 Ambas actividades proporcionan, al menos, el $50 \%$ de la proteína de origen animal a millones de personas en países de bajos ingresos.
} 
a través del cual el cambio climático afecta la "seguridad alimentaria"8 que permite garantizar, junto al acceso al agua, la cura de las enfermedades, el saneamiento y la nutrición de las personas. Esta se pone en riesgo con las sequías, las inundaciones y los fenómenos meteorológicos extremos, que acentúan problemas preexistentes como ser las pautas estacionales de la inadecuación en la disponibilidad y el acceso a los alimentos. Además, el cambio climático podría comprometer la inocuidad de los alimentos por el aumento de agentes patógenos, la contaminación del agua potable con algas y los mariscos con cianotoxinas, el incremento del riesgo de contaminación de legumbres y cereales almacenados con microtoxinas, el aumento del uso de agrotóxicos con sus potenciales efectos nocivos para contrarrestar los cambios de pautas en las enfermedades de plantas y animales, y la alteración en la calidad nutricional y el rendimiento ${ }^{9}$ de cultivos alimentarios fundamentales ${ }^{10}$.

Si bien la agricultura podría incidir de manera decisiva, no es la única causa que pone en peligro la seguridad alimentaria a causa del cambio climático: los fenómenos meteorológicos extremos también podrían poner en peligro los ingresos y los medios de vida de la población urbana que se vería impedida de acceder a los alimentos.

El cambio climático afecta la disponibilidad de alimentos porque modifica el rendimiento de los cultivos, la población de peces y la pro- ducción y la sanidad animal, además de influir negativamente en los ingresos y los medios de vida rurales. Todo esto pone en riesgo la seguridad alimentaria y, por esta razón, el Papa Benedicto XVI (2008a), en un mensaje enviado a una conferencia organizada por la FAO, mostraba la necesidad de elaborar nuevas estrategias de lucha contra la pobreza y de promoción del desarrollo rural, además de realizar reformas estructurales que permitan afrontar los desafíos de la seguridad alimentaria y del cambio climático.

La volatibilidad climática, las sequías, las inundaciones afectan en primer lugar a los más vulnerables: los pequeños agricultores y los trabajadores agrícolas que podrán ver reducida sus ya paupérrimas ganancias y ocasionar una pérdida de activos que menoscabe la futura generación de ingresos. Todo esto hará que, a menor disponibilidad de alimentos, su precio suba, lo cual traerá mayores perjuicios para ese sector de la población que destina el mayor porcentaje de sus ingresos solo a su alimentación. Los cambios en las posibilidades de acceso a los alimentos repercutirán en la situación nutricional de las personas pobres $y$, entre ellos, afectará especialmente a los niños, tanto por la falta de alimentos como por el aumento de patógenos presentes en ellos y la escasez de agua potable para higiene.

El problema del acceso a los alimentos (principalmente en niños pequeños) puede derivar en una desnutrición crónica que afecta

\footnotetext{
8 La Cumbre Mundial sobre la Alimentación de 1996 definió de esta manera la "seguridad alimentaria": "Existe seguridad alimentaria cuando todas las personas tienen en todo momento acceso físico y económico a suficientes alimentos inicuos y nutritivos para satisfacer sus necesidades alimenticias y sus preferencias en cuanto a los alimentos a fin de llevar una vida activa y sana" (FAO, 2009, p. 1).

9 Durante el período comprendido entre 1980 y 2008, hubo un descenso del 5,5 \% en la producción de trigo y 3,8 \% en la de maíz a escala mundial, en comparación con los que se habrían obtenido si el clima se hubiese mantenido estable.

${ }^{10}$ El grano de trigo podría tener un $9 \%$ menos de zinc, $5 \%$ menos de hierro y $6 \%$ menos de proteínas. De la misma manera, en diferentes porcentajes, se vería alterada la composición de nutrientes en el maíz y la soja.
} 
de por vida la capacidad de progreso y, por lo tanto, de las sociedades enteras a las que pertenecen los afectados.

La desnutrición, especialmente aquella provocada por la falta de alimentos (y estímulos afectivos) en los dos primeros años de vida, genera en los niños una lesión cerebral que solo les permite desarrollar un $35 \%$ o $45 \%$ del cerebro, por lo cual algunos van a ser capaces de sumar y restar pero no de multiplicar y dividir, otros van a ser capaces de esto pero no de otro ejercicio más complejo, lo cual hará que abandonen la escuela, no por falta de ganas, sino porque no son capaces de comprender (Albino, 2010). De esta manera, gira la rueda de la pobreza de la cual, en estas condiciones, se hace casi imposible salir.

Los efectos del cambio climático sobre la producción y la productividad de los sectores de la agricultura se traducirán en repercusiones económicas y sociales casi siempre negativas, que afectan de igual modo los ingresos de los hogares como de las naciones: para el año 2033, se proyecta un incremento de 122 millones de personas que vivirán en condiciones de extrema pobreza. La disminución de los ingresos en el sector explica la mayor parte del incremento de la pobreza provocada por el cambio climático, seguido por las repercusiones en la salud como consecuencia del alza de la temperatura y la poca productividad de la mano de obra. Las perturbaciones climáticas reducen notablemente la productividad de las cosechas, restringen el acceso a los alimentos y afectan al capital cuando los activos quedan destruidos o los agricultores se ven obligados a venderlos para superar la crisis de ingresos. Esto hace que merme la capacidad de invertir, con las obvias consecuencias para la seguridad alimentaria futura. En este sentido, se prevé que el cambio climático provoque una disminución sustancial de la tasa de autosuficiencia alimentaria en los países en desarrollo de alrededor de $12 \%$ para 2050 (Fao 2016).

El cambio climático también podría provocar alteraciones en los modelos de inversión. La incertidumbre desincentiva la inversión en la producción agrícola, lo que podría contrarrestar los beneficios de las alzas en los precios de sus productos, especialmente en los pequeños agricultores que carecen de fácil acceso a créditos y seguros. Esto genera un aumento de los llamados "cultivos de subsistencia" de bajo riesgo y escaso beneficio, con pocas posibilidades de utilizar insumos y poner en práctica nuevas tecnologías.

Las repercusiones del cambio climático variarán según la región, el país y, en última instancia, la situación de vulnerabilidad en este se encuentre inmerso. Para el 2050, en relación con un mundo sin cambio climático, se espera que los rendimientos medios mundiales de los cultivos disminuirán entre un $5 \%$ y un $7 \%$ mientras que la superficie cosechada aumentará un $4 \%$. Vemos así que el impacto del cambio climático sobre la producción será mínimo, pero la superficie cosechada y los precios de los alimentos básicos se incrementarán dos veces a lo previsto sin variaciones climáticas.

El problema del incremento de insectos y plagas debido al cambio de temperaturas también afecta al turismo, actividad que da empleo directa e indirectamente a gran cantidad de trabajadores. En Neuquén, por nombrar un ejemplo, tenemos el problema del hantavirus, un virus transmitido por un roedor que puede poner en riesgo la vida de las personas. El problema de la enfermedad se ha visto incrementado por el cambio climático, puesto que los inviernos menos crudos han permitido una mayor supervivencia de las crías de los roedores y, con el aumento de esta población, se incrementa tanto la posibilidad de contagio del virus a personas (Lugones, 2014). A causa 
del riesgo real de contagio y el miedo de las personas, en el 2019, se vio afectado el turismo en las provincias de Chubut, en la zona de Epuyén, en Neuquén, en San Martín de los Andes y en Río Negro, donde desde El Bolsón informaron que, por causa del hantavirus, se redujo en un $30 \%$ la cantidad de turistas que llegaron en relación con los esperados (La Voz del Interior, 2019). Esto, a su vez, generó la necesidad de reformar la recaudación impositiva para los implicados, lo que seguramente habrá impactado en los servicios sociales.

De no haber cambio climático, durante el período 2010-2050, la mayoría de las regiones experimentaría una reducción de personas en riesgo de padecer hambre. Sin embargo, las proyecciones son que para el 2050 más de 40 millones más de personas podrían encontrarse en riesgo de subalimentación en comparación con una situación sin variaciones climáticas.

\section{La migración climática}

Las condiciones climáticas contribuyen a poner en peligro la supervivencia de millones de personas que viven en zonas vulnerables y se ven obligados a dejar su tierra para tratar de mejorar sus condiciones alimenticias. Según un estudio de la Environmental Justice Foundation (2017), "el cambio climático creará la mayor crisis de refugiados que haya visto el mundo", aunque las migraciones internas (dentro del propio país) son mucho mayores que las de quienes emigran a otros países. Esto ocurre gracias una serie de factores que llevan a las personas a trasladarse y que convierten al cambio climático en un motivo para inhibir o impulsar la emigración.

El Banco Mundial (2018) ha elaborado un informe para que los países se preparen a estas migraciones internas, especialmente en África Subsahariana, Asia Meridional y América Latina donde se espera que para el 2050 sumen un total de 140 millones de migrantes internos motivados por las sequías, las malas cosechas, el aumento del nivel del mar, las mareas de tormenta, todas derivadas del cambio climático. Hay países, como Bangladés, que casi la mitad de la población depende de la agricultura, por lo que los cambios en la disposición del agua y en la productividad de los cultivos podrían provocar importantes desplazamientos de la población; en África, el país más complicado por el cambio climático es Etiopía, donde entre el $60 \%$ y el $85 \%$ de la población vive de los recursos naturales; en América Latina, se proyecta que para el 2050 habrá 17 millones de migrantes internos.

Sin embargo, hay medidas que pueden tomarse ante estas previsiones, como ser: reducir las emisiones de gases de efecto invernadero; incorporar las migraciones climáticas en la planificación del desarrollo, ya que esta tendencia repercutirá tanto en las zonas urbanas como en las periurbanas, que deberán prepararse mejorando la infraestructura de viviendas y transporte, los servicios sociales y las oportunidades de empleos; diversificar los medios de vida para que las poblaciones puedan encontrar otra forma de subsistencia sin necesidad de abandonar su tierra; planificar y prepararse adecuadamente para tratar este fenómeno según la escala y los patrones que seguirán estas migraciones.

El citado informe del Banco Mundial (2018) nos anticipa que la escala de las migraciones internas provocadas por el cambio climático aumentará hasta el año 2050 y luego se acelerará, y que esto perjudicará a los más pobres, en tanto las personas vulnerables tienen menos oportunidades de adaptarse en el lugar adonde viven o de alejarse de los riesgos $y$, cuando migran, lo hacen como último recurso. En cambio, los más vulnerables de todos no podrán trasladarse y quedarán atrapados 
en zonas que serán cada vez más inviables. Por eso, es muy importante también tener en consideración que, a pesar de la migración prevista, muchas personas seguirán viviendo en el mismo lugar por lo que habrá que invertir en infraestructura con un enfoque inteligente respecto al clima, diversificar las actividades comerciales, establecer sistemas de protección financiera que respondan mejor a las necesidades de grupos vulnerables, entre las acciones más urgentes.

Sin embargo, la adaptación a los lugares vulnerables tiene sus límites, y no siempre parece ser una buena opción, puesto que existe la posibilidad de que las personas se vean inducidas a quedarse en sitios donde sus condiciones de vida se están deteriorando. Por ejemplo, 20 millones de personas en Bangladés están sufriendo las consecuencias en su salud porque el aumento del nivel del mar ha generado la intrusión del agua salada en sus reservas de agua potable.

Es probable que dentro de los países surjan puntos críticos de inmigración y emigración inducida por el clima, que traerá consecuencias significativas y que comenzarán a identificarse más claramente en el 2030. Se estima que para el 2050 su número y su extensión geográfica se incrementará considerablemente (Banco Mundial, 2018). Hablamos de áreas que se vuelven cada vez más marginales y que pueden abarcar ciudades situadas en zonas bajas, costeras $y$, por tanto, vulnerables al aumento del nivel del mar y áreas de elevado estrés hídrico y agrícola, cuyos pobladores migran a sitios con condiciones climáticas más favorables para la agricultura o a las ciudades, que muchas veces pueden ofrecer mejores oportunidades para desarrollar diferentes medios de subsistencia, pero no siempre logran incluir a los migrantes en sus tareas productivas. En estos casos, los inmigrantes pasan a engrosar los números cada vez más grandes de pobreza y marginalidad que están presentes, como vidas paralelas, en las grandes metrópolis.

Para evitar esta situación, es necesario un contexto propicio para la inmigración a través de la creación de empleo y programas de capacitación. Estas estrategias que apoyan la migración interna también lo deben hacer con los habitantes de las comunidades de origen y destino. Un ejemplo de esta situación es la de la ciudad de Tarawa Sur, la capital de Kiribati, que vio incrementada su población de 1600 en 1947 a 50000 en la actualidad, y se convirtió así en una de las zonas más densamente pobladas del planeta debido a que otras islas de su nación se volvieron inhabitables por la elevación del nivel del mar. Si bien en Kiribati llueve frecuentemente, los tanques necesarios para recolectar agua de Iluvia son escasos y gran parte de la población local depende de acuíferos para beber agua, aunque la existencia de estos también está en peligro ya que, si se sigue elevando el nivel del mar, podrían ser contaminados por este, lo cual llevaría sin dudas a una gran crisis humanitaria (La Nación, 2020).

Este mismo país, conformado por 33 islas de las cuales solo 22 están habitadas, nos servirá también para ejemplificar lo que es la emigración forzada, puesto que se espera que en quince años Kiribati (al igual que Maldivas y Tuvalu) desaparezcan como consecuencia de la elevación del nivel del mar, siendo uno de los lugares más vulnerables del mundo al cambio de temperatura. Si bien Kiribati posee la reserva marina más importante del Pacífico Sur, el calentamiento global dificulta la reproducción de arrecifes en la zona, lo cual incrementa aún más los riesgos de aumento del nivel del mar.

Aquí se puede ejemplificar aquello que ya hemos dicho, cómo aquellos que participan en menor medida en las emisiones de gases de 
efecto invernadero - ya que es uno de los países más pequeños, con una extensión de 811 kilómetros cuadrados - son los que sufren con mayor gravedad los efectos del cambio climático y, si no media un cambio radical, 100000 personas se quedarán sin hogar y se convertirán en refugiados climáticos. Porque, como dice António Guterres (2011), secretario general de la ONU, las personas que se ven obligadas a dejar sus lugares de origen para emigrar a otros países donde poder sobrevivir no deben ser considerados inmigrantes comunes, sino que deben adquirir el rango de "refugiados" con todos los derechos que eso conlleva, porque ellos no se mudan voluntariamente, sino que abandonan cada vez más sus hogares

a causa de la interacción entre la degradación ambiental, los peligros naturales y el cambio climático y los efectos de la rápida urbanización, la escasez de agua y la inseguridad alimentaria y energética, agravada por "la desertificación, la sequía, las inundaciones y la creciente gravedad de los desastres (Türk como se cita en Goodwin-Gil y McAdam, 2017, p. 6).

En América Latina, los desplazamientos por motivos climáticos representan el $24 \%$ del total mundial, el tercer puesto después de Asia del Este y el Pacífico. Solo en el año 2017, en toda América, 4,5 millones de personas se vieron obligadas a desplazarse por motivos climáticos, de los cuales 3 millones lo han hecho en solo un mes a causa de los huracanes Harvey, Irma y María. En Sudamérica, entre el año 2000 y el 2015, se contó un total de 8 millones de migrantes climáticos, mientras que entre el 2008 y el 2014, Colombia, Chile y Brasil estuvieron dentro de los 20 países del mundo con mayor número de desplazados por problemas climáticos.

\section{Megaminería ${ }^{11}$}

Existen ciertas actividades comerciales que, ya en condiciones normales, son perjudiciales para las zonas donde se desarrollan, pero que, en circunstancias de cambio climático, implican empujar a sus pobladores directamente a la pobreza. Nos referimos aquí a la megaminería que, lamentablemente, presenta grandes emprendimientos en varias provincias argentinas.

En sí misma, la megaminería o minería a cielo abierto puede ser considerada enemiga del medioambiente debido a que usa toneladas de sustancias contaminantes, tiene grandes necesidades energéticas que satisface con electricidad y combustibles fósiles, utiliza elevados volúmenes de agua por largos períodos de tiempo, genera drenaje de ácidos de las minas, provoca altos niveles de tráfico $y$, cuando termina su explotación, deja importantes residuos ambientales, además de los pasivos sociales.

Como podemos ver, es una actividad que afecta a la sociedad, en general, y a los pobres, en particular. Pero no solo eso: es además una actividad que repercute de manera significativa en el incremento del cambio climático, ya que es uno de los mayores factores de generación de gases de efecto invernadero $y$, junto con la industria metalúrgica, es la responsable del 20 $\%$ de las emisiones globales de estos gases.

\footnotetext{
${ }^{11}$ Para saber más acerca de la megaminería, pueden consultar el manual Hablemos de megaminería de la Unión de Asambleas ciudadanas de Chubut (s.f), el ensayo "Basureros nucleares" (Buenas Tareas, 2012), el texto "Das Neves otorgó yacimiento de uranio o basurero nuclear a una compañía inglesa. Chubut tendrá su nuevo basurero nuclear" (Hualaue, 2010) y/o el artículo de Acción Ecológica (2010).
} 
Las fundiciones metalúrgicas demandan grandes cantidades de energía en los procesos de remoción de humedad, calentamiento de menas, fusión, recristalización, destilación, electrólisis, entre otros. A su vez, la producción de material particulado de plomo o azufre alteran la composición atmosférica local y regional, y provoca que la atmósfera se vuelva más seca y caliente. También, la extracción de carbón y su posterior quema para termoeléctricas son responsables directos del cambio climático a causa de la combustión de este hidrocarburo y no hay que dejar de considerar que durante el transporte de los productos se emiten también muchos gases con efecto invernadero: tan solo un camión de los utilizados en tareas de estas mineras puede llegar a superar el consumo de 6000 litros de combustible por día de trabajo.

Además del calentamiento directo ocasionado en atmosfera por la emisión de óxidos de nitrógeno, ozono y metano $(\mathrm{CH} 4)$, la industria minera incrementa indirectamente el calentamiento global al ocupar tierras agrícolas fértiles, generar la pérdida de bosques causando deforestación, degradar los suelos y expandirse a territorios indígenas, quienes han cuidado por miles de años los bosques que regulan el clima de la tierra.

\section{CONCLUSIÓN}

La lucha contra la pobreza se presenta como un deber moral de toda la humanidad que a los cristianos interpela de manera especial, ya que en cada hombre que sufre vemos a un hermano, hijo del mismo Padre, y porque sabemos que la pobreza es fruto del pecado que debemos combatir, primero en nosotros mismos y luego en la sociedad en general.

Como hemos visto, el cambio climático genera en las poblaciones menos favorecidas re- percusiones gravísimas que los condenan a una vida llena de carencias donde deben luchar diariamente para sobrevivir. Pero, también, hemos visto que la responsabilidad por esta situación ambiental y atmosférica está principalmente en aquellos que no sufren estos daños o, al menos, no padecen sus consecuencias de forma directa. Por eso, la lucha contra el cambio climático debe realizarse mediante un cambio de estilo de vida, producción y consumo. Un cambio que es moral y técnico, que implica abandonar el uso intensivo de combustible fósil y reemplazarlo por energías limpias y renovables, y limitar la deforestación para promover la agricultura. Este cambio se presenta como parte de la lucha por la justicia social, trabajo en el cual todos deberíamos sentirnos urgidos a involucrarnos, puesto que todos, en mayor o menor medida, colaboramos en la emisión de gases de efecto invernadero.

En la actual situación de pandemia, gracias a las cuarentenas obligatorias en gran parte del mundo, las emisiones de $\mathrm{CO}^{2}$ responsables del cambio climático se redujeron en forma significativa. Sin embargo, esto no se traduce necesariamente en un gran avance en la lucha contra el cambio climático. Por el contrario, esta situación sí es un cambio significativo en la vida de muchas personas que han caído en la pobreza. Estos nuevos pobres que engrosan las filas de los ya existentes obligan a las sociedades en general, y a los gobiernos en particular, a pensar programas especiales para aliviar la situación en estos momentos de recesión, generar empleos genuinos y poner en marcha distintos programas sociales.

\section{REFERENCIAS BIBLIOGRÁFICAS}

Acción Ecológica. (29 de marzo de 2010). Minería y cambio climático. Ecoportal. Recuperado de https://www.ecoportal.net/ 
temas-especiales/mineria/mineria_y_cambio_climatico/

Albino, A. (2010). Gobernar es poblar. Argentina: Editorial Logos.

Alejandro Beletzky. (21 de junio de 2018). "Quieren convertir la Patagonia en un basurero nuclear" [Entrada de blog]. Movimiento Antinuclear de Zárate y Campana. Recuperado de https://movimientoantinuclearzc.wordpress.com/2018/08/02/quieren-convertir-la-patagonia-en-un-basurero-nuclear/ [13 de febrero de 2020].

Antonio Cerrillo. (1 de agosto de 2018). Muertes por calor extremo. La Vanguardia. Recuperado de https://www.lavanguardia. com/natural/20180801/451180103666/ ola-calor-aumento-mortalidad-futuro-calentamiento.html [5 de enero de 2020].

António Guterres. (7 de diciembre de 2011). Statement by Mr. António Guterres, United Nations High Commissioner for Refugees, Intergovernmental Meeting at Ministerial Level to mark the 60th anniversary of the 1951 Convention relating to the Status of Refugees and the 50th anniversary of the 1961 Convention on the Reduction of Statelessness. The UN Refugee Agency. Recuperado de https://www.unhcr.org/admin/ hcspeeches/4ecd0cde9/statement-mr-antonio-guterres-united-nations-high-commissioner-refugees.html [30 de octubre de 2019].

Banco Mundial. (19 de marzo de 2018). \#Groundswell: Prepararse para las migraciones internas provocadas por impactos climáticos. Recuperado de https://www. bancomundial.org/es/news/infographic/2018/03/19/groundswell---preparingfor-internal-climate-migration [23 de mayo de 2019].

Benedicto XVI. (6 de julio de 2006). Mensaje del Papa Benedicto XVI a su Santidad Bartolomé
I, Patriarca de Constantinopla. Recuperado de http://www.vatican.va/content/benedict-xvi/es/letters/2006/documents/hf_ ben-xvi_let_20060706_bartolomeo-i.html

Benedicto XVI. (2 de junio de 2008a). Mensaje del Santo Padre Benedicto XVI a los participantes de la cumbre de la FAO celebrada en Roma. Recuperado de http://www.vatican. $\mathrm{va/content/benedict-xvi/es/messages/}$ pont-messages/2008/documents/hf_benxvi_mes_20080602_fao.html [23 de mayo de 2019].

Benedicto XVI. (13 de octubre de 2008b). Mensaje del Papa Benedicto XVI a la FAO en ocasión de la Jornada Mundial de la Alimentación. Recuperado de http:// www.vatican.va/content/benedict-xvi/ es/messages/food/documents/hf_benxvi_mes_20081013_world-food-day-2008. html [8 de septiembre de 2019].

Buenas Tareas. (18 de diciembre de 2012). Basureros Nucleares. Recuperado de https:// www.buenastareas.com/ensayos/Basureros-Nucleares/6894036.html [13 de febrero de 2020].

Cambio Climático Global. (s.f.). Consecuencias del cambio climático. [Entrada de blog]. Recuperado de https://cambioclimaticoglobal.com/consecuencias-del-cambio-climatico [8 de enero de 2020].

Cortina, A. (2017). Aporofobia, el rechazo al pobre. Un desafío para la democracia. Barcelona: Paidós.

Declaraciones de la Iglesia. (s.f.). Movimiento Católico Mundial por el Clima. Recuperado de https://catholicclimatemovement.global/es/church-statements-pastoral-lettersetc-es/ [23 de mayo de 2019].

Enviromental Justice Foundation. (2017). Protecting climate refugees. Recuperado de https://ejfoundation.org/what-we-do/climate/protecting-climate-refugees 
Faith Statements on the Enviroment. (s.f). Earth Ministry. Recuperado de https://earthministry.org/faith-statements/ [23 de mayo de 2019].

Francisco. (24 de mayo de 2015). Carta Encíclica Laudato Si del Santo Padre Francisco sobre el cuidado de la casa común. Recuperado de http://www.vatican.va/content/dam/ francesco/pdf/encyclicals/documents/ papa-francesco_20150524_enciclica-laudato-si_sp.pdf

Goodwin-Gil, G. S. y McAdam, J. (2017). ACNUR \& cambio climático, desastres y desplazamientos. Recuperado de https://www. acnur.org/5d4c9b7f4.pdf [ 24 de noviembre de 2019].

Hantavirus: caen las reservas en zonas aledañas a la afectada. (24 de enero de 2019). La Voz del Interior. Recuperado de https:// www.lavoz.com.ar/ciudadanos/hantaviruscaen-reservas-en-zonas-aledanas-afectada [27 de febrero de 2020].

Hualaue. (23 de noviembre de 2010). Das Neves otorgó yacimiento de uranio o basurero nuclear a una compañía inglesa. Chubut tendrá su nuevo basurero nuclear. [Entrada de blog]. Recuperado de https://identidadlra9.blogspot.com/2010/11/das-nevesle-otorgo-otro-yacimiento-de.html [13 de febrero de 2020].

Jonas, H. (1995). El principio de responsabilidad. Barcelona: Herder.

Juan Pablo II. (1 de enero de 1990). Mensaje de su Santidad Juan Pablo II para la celebración de la XXIII Jornada Mundial de la Paz. Recuperado de http://www.vatican.va/ content/john-paul-ii/es/messages/peace/ documents/hf_jp-ii_mes_19891208_xxiiiworld-day-for-peace.html [5 de mayo de 2019].

Juan Pablo II. (1 de mayo de 1991). Carta Encíclica Centesimus Annus del Sumo Pontífice
Juan Pablo II en el centenario de la Rerum Novarum. Recuperado de http://www.vatican.va/content/john-paul-ii/es/encyclicals/ documents/hf_jp-ii_enc_01051991_centesimus-annus.html

Kant, E. (1980). La fundamentación de la metafísica de las costumbres. Madrid: Espasa Calpe.

Kiribati, el país superpoblado del Pacífico Sur que será inhabitable en menos de 15 años. (21 de enero de 2020). La Nación. Recuperado de https://www.lanacion.com.ar/el-mundo/ kiribati-el-pais-superpoblado-del-pacificosur-que-sera-inhabitable-en-menos-denid2325888 [21 de enero de 2020].

Los Adobes, la mina de uranio que fue escenario de cuatro muertes dudosas. (8 de noviembre de 2016). El Patagónico. Recuperado de https://www.elpatagonico.com/ los-adobes-la-mina-uranio-que-fue-escenario-cuatro-muertes-dudosas-n1519489 [13 de febrero de 2020].

Lugones, J. R. (2014). Una tierra habitable para todos. Buenos Aires: Claretiana.

Milvia Morciano, M. (2012). Per una ecología dell' uomo. Antología di testi di Benedetto XVI. Vaticano: Librería Editora Vaticana.

Naciones Unidas. (s.f.). Cambio climático. [Entrada de blog]. Recuperado de https:// www.un.org/es/sections/issues-depth/ climate-change/index.html [5 de mayo de 2020].

Organización de las Naciones Unidas para la Alimentación y la Agricultura [FAO]. (2009). Declaración de la Cumbre Mundial sobre la Seguridad Alimentaria. Recuperado de http://www.fao.org/tempref/docrep/fao/ Meeting/018/k6050s.pdf

Organización de las Naciones Unidas para la Alimentación y la Agricultura [FAO]. (2016). El estado mundial de la agricultura y la alimentación. Cambio climático, agricultura 
y seguridad alimentaria. Recuperado de http://www.fao.org/3/a-i6030s.pdf [12 de mayo de 2019].

Pablo Vl. (14 de mayo de 1971). Carta Apostólica Octogesima Adveniens. Recuperado de http://www.vatican.va/content/ paul-vi/es/apost_letters/documents/hf_pvi_apl_19710514_octogesima-adveniens. html [5 de abril de 2019].

Pontificio Consejo Justicia y Paz. (2005). Compendio de la Doctrina Social de la Iglesia. Buenos Aires: Conferencia Episcopal Argentina.
The Lancet. (13 de noviembre de 2019). The 2019 report of The Lancet Countdown on health and climate change: ensuring that the health of a child born today is not defined by a changing climate. [Artículo de revista científica]. Recuperado de https:// www.thelancet.com/pdfs/journals/lancet/ PIIS0140-6736(19)32596-6.pdf [23 de febrero de 2020].

Unión de Asambleas Ciudadanas de Chubut. (s.f.). Hablemos de megaminería. Recuperado de https://megamineria.com.ar/hablemos-de-megamineria/ 
